\section{Aspectos introdutórios da TEORIA GERAL DO CRIME}

Sérgio de Oliveira Médici*

\section{Teoria geral do crime}

A teoria geral do delito constitui matéria indispensável à compreensão e à justa aplicação do Direito Penal em qualquer país civilizado do mundo.

O ponto inicial deste estudo deve situar-se na obra de Ernst von Beling ${ }^{1}$ de 1906, que introduziu o conceito de tipicidade ao lado de categorias já conhecidas de autores do final do século XIX, como Von Liszt (a antijuridicidade, a culpabilidade e a punibilidade)

\section{Significado da teoria geral do crime}

Por meio da teoria geral do crime são definidas as características comuns a todos os delitos previstos na legislação de um país.

Os crimes em espécie possuem características próprias. Caso contrário não teriam existência justificada. Assim, o homicídio é diferente de injúria ou de lesão corporal. $\mathrm{O}$ tipo de furto apresenta conceito distinto daquele referente ao roubo ou ao estelionato. Cada um deles indica a respectiva pena, cominada de acordo com a gravidade do crime, na concepção do legislador. Mas há, entre todos eles, circunstâncias, elementos, requisitos ou categorias comuns. Disso se ocupa a teoria geral do crime: apresentar conceitos genéricos, aplicáveis a todos os delitos.

\section{Aplicação prática da teoria geral do crime}

Por meio da teoria geral do crime, torna-se possível o correto ajuste dos fatos humanos aos tipos previstos nas espécies legais. Assim, o tipo de homicídio é definido em lei como matar alguém. Mas não basta demonstrar que uma pessoa deu causa à morte de outrem para aplicar a este fato o Direito Penal: é preciso indagar se o causador da morte agiu com dolo ou com culpa, se não

* Sérgio de Oliveira Médici é advogado, professor titular de Direito Penal do Centro Universitário de Araraquara (UNIARA), mestre em Direito Processual e doutor em Direito Penal pela Universidade de São Paulo Foi Promotor e Procurador de Justiça (Ministério Público do Estado de São Paulo) e membro da Comissão Revisora do Código Penal (Ministério da Justiça, 1998-1999). 1. Die Lehre vom Tatbestand. A respeito deste tema, v. Teoria dos Tipos Penais (Médici, 2004) repeliu uma injusta agressão (legítima defesa), se ele é ou não imputável etc. Caso contrário, bastaria um código com os conceitos de crimes em espécie (a Parte Especial), como acontecia com as legislações antigas. ${ }^{2}$ Penal.

A teoria geral do crime, portanto, estruturou cientificamente o Direito

\section{Conceito genérico de crime}

O Código Penal vigente refere-se ao crime em diversos dispositivos, ${ }^{3}$ sem contudo dedicar a ele um conceito genérico, aplicável a todas as infrações criminais ${ }^{4}$. O mesmo critério constava da redação original da Parte Geral de 1940, afastando-se da fórmula empregada pelo Código de 1890, que estabeleceu um conceito vago e praticamente inútil ao fato criminoso: "Crime é a violação imputável e culposa da lei penal"s.

Com isso, na elaboração do estatuto penal de 1940 e na reforma de 1984, o legislador transferiu a missão de conceituar genericamente o fato-crime para a doutrina, evitando a repetição da fórmula equivocada do Código de $1890{ }^{6}$

Os conceitos doutrinários apresentados a partir do início do século $\mathrm{XX}$ podem ser separados em formais, substanciais e analíticos, segundo o critério adotado pelo seu formulador.

Os conceitos formais representam a concepção do Direito sobre a infração penal e consideram crime a violação da lei penal: crime é o fato humano que viola a lei penal; os substanciais exprimem a concepção do ponto de vista da sociedade e dão relevo ao aspecto interno ou essencial: crime é a conduta

2. A Parte Especial precedeu, historicamente, a Parte Geral, pois as legislações antigas limitavamse a expressar as condutas consideradas proibidas. O primeiro código a apresentar uma Parte Geral foi o da Baviera, de 1751

3. As referências começam no art. 1. ("não há crime sem lei anterior que o defina") e podem ser notadas em vários dispositivos posteriores, como nas regras da abolitio criminis (art. $2 .^{\circ}$ ), do tempo e do lugar do crime $\left(\operatorname{artigos} 4{ }^{\circ} \mathrm{e} 6^{\circ}\right.$ ), da territorialidade e da extraterritorialidade (artigos $5^{\circ}$ e 7. ${ }^{\circ}$ ), da relação de causalidade (art. 13) etc.

4. Cada espécie de crime tem o seu conceito. Matar alguém, por exemplo, é o conceito do tipo de homicídio, mas que só pode ser aplicado a esta espécie de delito. AParte Especial do Código, portanto, dedica-se fundamentalmente à concepção dos preceitos e das respectivas cominações de penas.

5. No art. $7 .^{\circ}$. Ao mencionar a imputabilidade e a culpabilidade, o conceito legal exprime a idéia em torno dos elementos do crime antes da criação da teoria da tipicidade, de Beling: o crime era o fato imputável, isto é atribuível a quem deu causa ao resultado, e culpável, compreendendo o dolo e a culpa em sentido estrito.

6. Na Lei de Introdução ao Código Penal e à Lei das Contravenções Penais (Decreto-lei n. 3914 de 9 de dezembro de 1941, encontramos um conceito formulado para distinguir as duas espécies de infrações penais, mas somente quanto às conseqüências (penas): "Considera-se crime a infração penal a que a lei comina pena de reclusão ou de detenção, quer isoladamente, quer alternativa ou cumulativamente com a pena de multa; contravenção a infração a que a lei comina, isoladamente, pena de prisão simples ou de multa, ou ambas, alternativa ou cumulativamente." 
humana que lesa ou expõe a perigo de lesão um bem jurídico legalmente protegido; finalmente os analíticos, que buscam o conceito a partir dos elementos constitutivos do crime, refletindo a concepção da ciência jurídico-penal.

Foram as formulações analíticas que despertaram maior interesse e propiciaram grandes debates entre os doutrinadores, não havendo até hoje uma concepção aceita por ampla maioria dos penalistas. Neste aspecto, o crime fo inicialmente conceituado como a ação típica, antijurídica, culpável e punível, considerando então os quatro elementos do delito.?

Podemos visualizar este conceito utilizando a figura geométrica de um retângulo, com os quatro componentes do crime:

CRIME

\begin{tabular}{|ll|}
\hline Tipicidade & Antijuridicidade \\
Culpabilidade & Punibilidade \\
\hline
\end{tabular}

A grande maioria dos doutrinadores, entretanto, não considera a punibilidade como elemento constitutivo do crime, mas sim mera conseqüência da infração penal. Basta lembrar, neste aspecto, que a ocorrência de uma causa de extinção da punibilidade, como a morte do agente ou a prescrição, não faz desaparecer o crime. Há, apenas, a impossibilidade do exercício do jus puniendi por parte do Estado 8 .

Passaram a ser três, então, os elementos do crime, despontando a chamada teoria causalista ou tradicional. Faremos a representação desta concepção por meio de um triângulo:

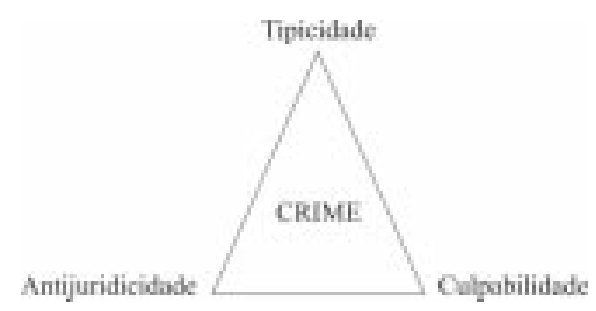

7. Na essência, o conceito analítico pode ser também considerado formal, pois os seus elementos constitutivos são extraídos da lei: tipicidade (previsão legal, princípio da legalidade), ilicitude ou antijuridicidade (contrariedade à lei, ou à ordem jurídico-legal) e culpabilidade (ou reprovação social, igualmente definida por meio de dispositivos legais)

8. Também não integram o conceito genérico de crime as condiç̃es objetivas de punibilidade ou de procedibilidade, como a sentença que decreta a falência em relação aos crimes falimentares ou a representação do ofendido nos crimes de ação penal pública condicionada, pois são requisitos objetivos ou processuais de determinados delitos.
A ação ou omissão (ou conduta) do agente, de acordo com a concepção causalista, é despida de qualquer valoração: basta que dê causa a um resultado. As questões relativas ao elemento subjetivo (dolo) e normativo (culpa), integram a culpabilidade, ao lado da imputabilidade e da exigibilidade de outra conduta.

A primeira reação significativa a esse conceito partiu de Hans Welzel que formulou a teoria finalista da ação, partindo do pressuposto de que toda ação humana está dirigida a um fim. Com isso, dolo e culpa foram retirados da culpabilidade e passaram a caracterizar a conduta, integrando assim o fato típico.

O fato típico, para o finalismo, compõe-se de conduta (dolosa ou culposa), resultado, relação de causalidade e tipicidade. A culpabilidade, despida de dolo e culpa, passou a ter os seguintes elementos: imputabilidade, potencial conhecimento da ilicitude (em substituição ao dolo e à culpa) e exigibilidade de conduta diversa.

Houve várias interpretações do finalismo, com muitos adeptos excluindo a culpabilidade da conceituação de crime. Para esta posição radical, crime passou a ser concebido simplesmente como fato típico e ilícito. A culpabilidade passou a ser entendida como mero pressuposto para a imposição da pena. Simbolizamos esta corrente de pensamento com um círculo:

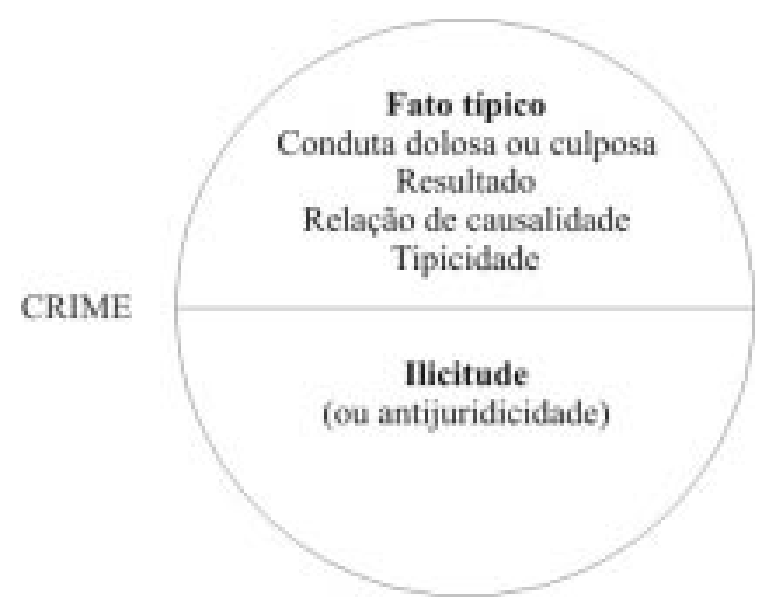

Mais aceitável a concepção do crime como fato típico, ilícito e culpável, numa visão unitária, mantendo-se as composições propostas pelo finalismo. $\mathbf{O}$ círculo pode ser assim representado. 


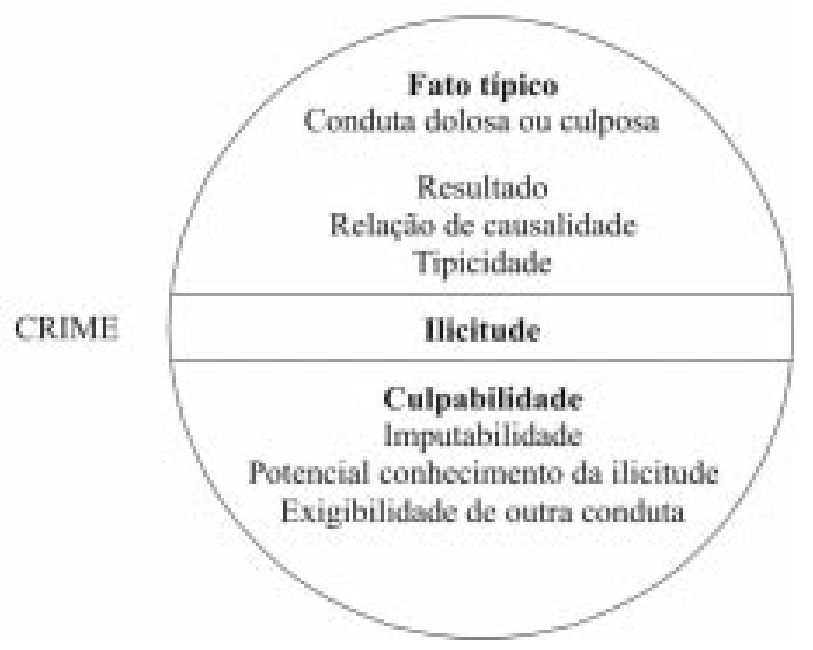

O principal argumento utilizado pelos finalistas radicais para excluir a culpabilidade do conceito do crime está na interpretação literal do texto legal: quando se refere à exclusão da ilicitude (art. 23) o Código diz que não há crime. Nas causas que excluem a culpabilidade, entretanto, o Código afirma que são inimputáveis, não são puníveis, são isentos de pena. ${ }^{9}$

Trata-se de posição que pode ser rebatida com a explicação de que o legislador procurou distinguir as causas de exclusão da ilicitude (utilizando a palavra crime) daquelas extintivas da culpabilidade (mencionando a punição) sem, contudo, declarar que somente o fato típico e a ilicitude integram o conceito de crime. Além disso, mostra-se pouco razoável considerar crime um fato não reprovado socialmente (ou seja, a sociedade não exige do agente comportamento diverso)..$^{10}$

Por outro lado, não integram o conceito genérico de crime, além da punibilidade, as condições objetivas de punibilidade ou de procedibilidade, como a declaração da falência nos crimes falimentares, a representação do ofendido nos crimes de ação penal pública condicionada etc.

\section{Fato típico}

Fato típico é o comportamento humano, doloso ou culposo, previsto em lei como crime, e que produz um resultado. Ou seja, a conduta do agente, para ser considerada típica, precisa estar definida em um tipo legal e causar uma ofensa ao bem jurídico protegido pela lei

9. Como se verifica nos artigos $22,26,27,28$, do CP.

10. Assinale-se ainda, como contra-argumento, que no art. 17, ao definir o crime impossível, o Código Penal declara que não se pune a tentativa..., referindo-se claramente a uma situação em que se exclui a tipicidade (e não a culpabilidade)
Compõem o fato típico, a conduta do agente (dolosa ou culposa), o resultado, a relação causal entre conduta e resultado e, finalmente, a tipicidade.

\section{Conduta}

O comportamento humano, que constitui o momento inicial de intervenção jurídico-penal, admite vários conceitos. Por isso, em torno de tais concepções assentaram-se as principais teorias relativas ao conceito genérico de crime.

De outra parte, salvo a ocorrência de circunstâncias especiais - como a habitualidade do agente nos crimes habituais (exercício ilegal da medicina, por exemplo), ou a qualidade do agente (crimes próprios, como os funcionais) pode-se dizer que o Direito Penal baseia-se no fato cometido pelo agente e não na figura deste. Em outras palavras: o Direito Penal deve ser o Direito Penal do fato (ou do ato) e não o Direito Penal do autor.

Este entendimento representa uma garantia pessoal, pois conceitos relativos ao agente são, regra geral, indefinidos. Basta confrontar, em relação ao homicídio, o conceito do fato (matar alguém), com o do autor (homicida, assassino). Ou o conceito de furto (subtrair, para si ou para outrem, coisa alheia móvel), com o de ladrão, larápio etc.

O Direito Penal verdadeiramente democrático e garantista, que respeita as liberdades individuais, deve limitar-se às definições de fatos e não de qualidades negativas do agente

Também não interessam ao Direito Penal comportamento de animais irracionais (salvo quando atuam como instrumentos de pessoa humana), bem como os fatos provocados exclusivamente por força da natureza - os chamados fenômenos naturais (exceto nas omissões penalmente relevantes).

Quanto às pessoas jurídicas, também não podem ser sujeitos ativos de crimes, não obstante forte corrente doutrinária em sentido oposto. O Direito Penal foi estruturado em função da conduta humana, como dolo, culpa, imputabilidade, erro, arrependimento etc., o que impede a extensão de sua aplicação aos entes morais

Ação (ou conduta) é o comportamento humano voluntário. Pode ser ativa (ação em sentido estrito) ou passiva (omissão). Trata-se do fazer ou do não fazer por parte do agente, com repercussão no mundo exterior, pois o direito penal não se ocupa com idéias, pensamentos ou cogitações.

O comportamento omissivo, entretanto, somente integra o fato tipo se considerado relevante. O Código disciplina esta questão no art. $13, \S 2{ }^{\circ}$, ao estabelecer que a omissão é penalmente relevante quando o agente: 1) tenha por lei obrigação de cuidado, proteção ou vigilância; 2) de outra forma, assumiu a responsabilidade de impedir o resultado; 3 ) com seu comportamento anterior criou o risco da ocorrência do resultado. 
$\mathrm{Na}$ primeira hipótese estão as questões regulamentadas, direta ou indiretamente, por lei. ${ }^{11} \mathrm{Na}$ segunda, temos os casos dos chamados contratos, formais e informais, em sentido amplo. ${ }^{12} \mathrm{Na}$ última, o agente cria para a vítima uma situação de perigo, não podendo omitir-se no salvamento dela. ${ }^{13}$

$\mathrm{O}$ fato provocado por caso fortuito - o que ocorre por acontecimento estranho à vontade do agente - ou por força maior - em que o agente é impelido por coação física de outrem, conseqüentemente, não será considerado conduta típica.

\section{Teoria causalista}

Para a doutrina causal, basta que o comportamento humano voluntário tenha dado causa a um resultado para ser considerado conduta. Dolo e culpa só serão examinados na culpabilidade. A principal expressão do causalismo é Franz von Liszt (1950, p.297), para quem ação é a causa voluntária, ou não impeditiva, de uma modificação no mundo exterior

Reflete, em suma, o pensamento positivista do final do século XIX, que aplica métodos e leis naturais às ciências humanas.

A maior deficiência desta teoria está na separação entre conduta e o dolo ou a culpa, fato que impõe duas análises distintas da ação: uma como causa do resultado, outra como elemento da culpabilidade. Com isso, temos uma tipicidade provisória, pois o ajuste definitivo da conduta a um tipo penal só será possível com a definição do dolo ou da culpa (que é objeto da culpabilidade).

\section{Teoria finalista}

A teoria finalista, criada por Hans Welzel, considera que todo comportamento humano dirige-se necessariamente a um fim determinado: ação é o exercício da atividade final. Conseqüentemente, dolo ou culpa integram a conduta (e não a culpabilidade).

A atividade final da conduta pode ser desdobrada em duas fases - uma interna, outra externa.

A primeira etapa compreende a intenção do agente, no âmbito do pensamento. Por ex.: comparecer à aula, a uma cerimônia religiosa, a um espetáculo esportivo. Ou praticar um fato definido como crime.

11. Tais como a obrigação dos pais em alimentar os filhos e de zelar pela saúde dos mesmos; dos diretores do presídio em assegurar a vida e integridade física dos presos; dos policiais em garantir a segurança das pessoas.

12. Como o vigilante particular, o salva-vidas, o guia do cego.

13. O exemplo clássico é o do nadador experiente que convida um principiante para atravessar um rio a nado e, depois, não lhe presta ajuda. Aqui se ajusta também o comportamento do proprietário de animal bravo que o expõe e se omite diante do ataque do irracional a uma pessoa.
Para executar a atividade final, o agente seleciona os meios necessários e a maneira pela qual atingirá seu objetivo. Assim, para comparecer a um evento, a pessoa vai escolher entre um automóvel, um ônibus, o metrô, ou se fará o percurso a pé. Também compõem esta fase outras circunstâncias como a reserva do dinheiro para o transporte, a necessidade de alimentação no trajeto, a roupa que usará etc. São os chamados efeitos concomitantes que, uma vez adotados pelo agente, passam a integrar a ação.

A segunda fase surge no momento em que a ação deixa de ser mera cogitação (a seleção dos meios e modos de execução e ponderação dos efeitos concomitantes) e se transforma na busca de realização da meta a ser alcançada. Agora, temos a exteriorização da atividade humana - e a conduta pode ser juridicamente avaliada.

O raciocínio genérico aqui exposto pode ser adaptado ao campo penal: na primeira fase o agente se propõe a praticar um crime, escolhendo meios, modos de execução e considerando os efeitos concomitantes; na segunda etapa, busca a consumação do delito.

Se, v.g., o crime é de homicídio, o agente planeja sua execução com os meios (como um revólver, uma faca), os modos (de emboscada, à traição, mediante dissimulação) e possíveis efeitos concomitantes (intervenção de outras pessoas), para depois praticar o ataque contra o ofendido.

Mas a intervenção do Direito Penal também pode ocorrer sobre os meios e modos empregados ou sobre os efeitos concomitantes, se a finalidade do agente for lícita ou indiferente ao âmbito criminal. Assim, se no percurso da casa à escola (finalidade lícita) o agente conduz veículo automotor em velocidade acima da permitida e causa acidente com vítima pessoal, a valoração penal recai sobre o modo de conduta (imprudência) e nos efeitos concomitantes (lesão corporal ou morte de outras pessoas)

Desta forma, a teoria finalista explica a punição do crime culposo, no qual a objetividade final do agente, em geral, é lícita e até louvável (chegar a tempo a uma solenidade religiosa, ao trabalho), mas os meios e modos empregados e os efeitos concomitantes são considerados penalmente relevantes.

\section{Teoria social}

Uma terceira corrente, denominada teoria social da ação, busca conciliar o causalismo com o finalismo. Concebida por Eberhard Schimidt, Johannes Wessels e Hans-Heinrich Jescheck, entre outros, esta teoria considera não só os aspectos causal e finalístico da ação, mas também o social: ação é o comportamento humano socialmente relevante. Assim, a conduta será típica se constituir fato relevante para a sociedade.

Para Jescheck, o comportamento humano tanto pode consistir no exercício de uma finalidade, como pode restringir-se à causação de efeitos domináveis 
pelo homem ou, por último, pode manifestar-se pela simples inatividade diante de uma determinada ação que se espera. ${ }^{14}$

\section{Teoria da imputação objetiva}

Teoria que tem despertado grande controvérsia na doutrina é a da imputação objetiva, corrente pós-finalista, segundo a qual o resultado só pode ser atribuído ao agente se a sua conduta provocou um risco juridicamente não permitido ao bem jurídico protegido. Transcende o nexo causal, apresentandose como uma alternativa ao finalismo e cria o chamado funcionalismo penal (ou função do Direito Penal).

A imputação objetiva situa-se entre o nexo causal naturalístico e o elemento subjetivo. Ex: uma pessoa, dirigindo veículo em alta velocidade, atropela um pedestre que caminha na calçada. Trata-se de conduta de risco não permitida: a fato que causou lesões ou morte da vítima é atribuído (ou imputado) ao motorista. Somente depois é que se examina o dolo ou a culpa.

A teoria da conditio sine qua non, adotada pelo nosso Código Penal (art. 13), evita a regressão ao infinito por meio do dolo (o vendedor da arma para o homicida é excluído da corrente causal porque não conhecia a intenção do agente); para a imputação objetiva, não será típica a conduta do vendedor porque seu comportamento constitui um risco permitido.

Para o maior expoente desta teoria, Claus Roxin (1993, p.142), “a imputação objetiva, ao considerar a ação típica uma realização de um risco não permitido dentro do alcance do tipo, estrutura o ilícito à luz da função do Direito Penal." Em outras palavras, materializa-se o perigo no resultado ou aumentase o risco permitido com violação do dever de cuidado relevante. Portanto, pressupõe a realização de um perigo criado pelo agente e não coberto por um risco permitido dentro da abrangência do tipo.

Comprovada a causalidade material, deve-se verificar: a) se a conduta criou um perigo juridicamente proibido ao bem jurídico; b) se o resultado corresponde à concretização do perigo juridicamente desaprovado.

A concepção moderna da imputação objetiva é atribuída a dois juristas alemães: Karl Larenz (1927) e Richard Honig (1930). Para Larenz, a imputação objetiva descreve o juízo pelo qual determinado fato surge como obra de um sujeito, ou seja, a imputação consiste na tentativa de delimitação entre fatos próprio do agente e acontecimentos puramente acidentais. Assim, quando se diz que alguém causou determinado fato, afirma-se que o acontecimento é obra desse alguém, de sua vontade e não de um acontecimento acidental (como, por ex., o fato decorrente de caso fortuito). Considerando-se causa um conjunto de

14. V. a respeito desta teoria, Francisco de Assis Toledo (1991, p.99-102). condições, torna-se impossível selecionar apenas uma delas e imputar-lhe o resultado como seu.

Só a vontade dirige um processo causal e pode transformar as conseqüências acidentais em fato próprio do agente e a ele imputável. Por isso, a imputação de um fato é a relação entre acontecimento e vontade. Não se trata de mero juízo causal, mas processo teleológico. Em síntese: o fato é a realização da vontade; a imputação, o juízo que relaciona o fato com a vontade.

A imputação é chamada objetiva porque a possibilidade de previsão não é aferida com base na capacidade e conhecimento do agente, mas de acordo com critério geral e objetivo, o do "homem inteligente-prudente" (Prado, 2002).

Richard Honig também sustentou que o decisivo para a ordem jurídica não é a simples constatação da relação de causalidade, mas sim uma relação jurídica especial entre conduta e resultado. Não se trata de simplesmente aferir o nexo causal, mas de valorá-lo.

A causalidade fica definida com a constatação de que a conduta foi condição necessária para a ocorrência do resultado. Mas a comprovação da relação causal é insuficiente para que determinado resultado seja atribuído a alguém. Por isso, a imputação objetiva se propõe a aferir o significado dessa relação de causalidade com base em critérios fornecidos pelo ordenamento jurídico.

Para se saber se um fato pode ser imputado a alguém ou se decorre de acontecimentos fortuitos, deve-se lançar mão da finalidade objetiva. Podem ser imputáveis, portanto, os resultados que podem ser finalmente vislumbrados. "Imputável é aquele resultado que se pode conceber como orientado de acordo com finalidades", expressa-se Honig, na sua mais breve formulação. (Roxin, 1993, p. 146)

Como bem sintetiza Luiz Regis Prado (2002, p.447), por essa tese, "examinam-se não o conhecimento e a vontade atuais do autor, mas sim suas capacidades potenciais. Por isso se trata de uma imputação objetiva, já que esta não indica qual a relação psíquica existente entre o sujeito e o resultado a ele imputado. Só terão significado jurídico as relações causais regidas pela vontade humana, ou seja, os processos causais cujo curso seja passível de previsão e de direção. Apenas os resultados previsíveis e dirigíveis pela vontade são imputáveis e somente a imputação objetiva permite a afirmação da tipicidade de uma ação. A imputação objetiva do resultado é, dessa forma, pressuposto da tipicidade do comportamento."

Coube a Claus Roxin, portanto, a ampla divulgação da doutrina de Honig, a partir dos anos 70, desenvolvendo critérios próprios para a imputação objetiva. Só é imputável, para Roxin (1993, p.145-168), o resultado que pode ser finalmente previsto e dirigido pela vontade. Diante disso, os resultados não previsíveis ou não dirigíveis pela vontade, não podem ser considerados típicos. Também 
considera equiparada a possibilidade de domínio através da vontade pessoal (finalidade objetiva) à criação de um risco juridicamente relevante de lesão típica de um bem jurídico. A criação de um risco juridicamente desvalorado, consubstanciado em um resultado típico, configura o princípio geral da imputação objetiva. Propõe, então, uma teoria geral da imputação completamente desligada do dogma causal

Os critérios propostos por Roxin são: a) diminuição do risco: A vê uma pedra dirigida à cabeça de B, mas não pode impedir que B seja atingido. Então, desvia a pedra para outra parte do corpo de $\mathrm{B}$ em que o golpe é menos perigoso. Não haverá, neste caso, imputação a A pelos ferimentos sofridos por B; b) criação ou não criação de um risco juridicamente relevante: o herdeiro $A$ convence seu pai ou seu tio B a caminhar por um local onde raios podem cair durante uma tempestade; c) aumento ou falta de aumento do risco permitido: um fabricante, infringindo regulamentos, entrega a seus empregados pincéis de pelo de cabra chinesa não desinfectados e, em conseqüência, quatro trabalhadores contraem infecção devido a bacilos e morrem: tais mortes são imputáveis ao patrão, mesmo que a desinfecção prescrita não constituísse uma garantia absoluta de destruição dos bacilos; d) esfera de proteção da norma como critério de imputação: A atropela culposamente B e o mata, e a mãe deste, ao receber a notícia, começa a chorar e sofre um ataque nervoso. A não pode responder pela lesão sofrida pela mãe.

Para Roxin (1993, p.168), "cada vez ganha mais terreno a concepção de que para o Direito Penal é menos importante averiguar se e com que requisitos se pode qualificar como ação uma conduta humana, do que estabelecer quando e até que ponto se pode imputar como fundamento da responsabilidade, um resultado a determinada pessoa." E conclui perguntando se algum dia uma teoria geral da imputação poderá assumir de vez as funções que hoje se atribuem à teoria da ação.

\section{Referências bibliográficas:}

ANTOLISEI, Francesco. Manuale di diritto penale - parte speciale. 7.ed. Milano: Giuffrè, 1977.

BATTAGLINI, Giulio. Direito penal - parte geral. São Paulo: Saraiva, 1964.

BELING, Ernst von. La doctrina del delito-tipo. Buenos Aires: Depama, 1944.
BETTIOL, Giuseppe. Direito penal. São Paulo: Revista dos Tribunais, 1966. 1974

Instituições de direito e processo penal. Coimbra: Ed. Coimbra,

O problema penal. Coimbra: Coimbra Ed., 1967

BRUNO, Aníbal. Direito penal. 4.ed. Rio de Janeiro: Forense, 1984.

Crimes contra a pessoa. 3.ed. Rio de Janeiro: Ed. Rio, 1975.

BUSTOS RAMÍREZ, Juan. Manual de derecho penal - parte especial. Barcelona: Ariel S.A., 1986.

CARMIGNANI, Giovanni. Elementos de derecho criminal. Otero. Bogotá: Temis, 1979.

CARRARA, Francesco. Programa del curso de derecho criminal. Buenos Aires: Depalma, 1944.

CEREZO MIR, José. Curso de derecho penal español. 2.ed. Madrid: Tecnos, 1981.

Prefácio. In: PRADO, Luiz Regis. Bem jurídico-penal e constituição. São Paulo: Revista dos Tribunais, 1996.

CERNICCHIARO, Luiz Vicente; COSTA JÚNIOR, Paulo José da. Direito Penal na constituição. 2.ed. São Paulo: Revista dos Tribunais, 1990.

CHAVES CAMARGO, A.L. Culpabilidade e reprovação penal. São Paulo: Sugestões Literárias, 1994

Tipo penal e linguagem. Rio de Janeiro: Forense, 1982.

COSTA JÚNIOR, Paulo José da. Curso de direito penal. São Paulo: Ed. Saraiva, 1991.

CUELlO CALÓN, Eugenio. Derecho penal. 7.ed. Barcelona: Bosch, 1949 . 
DERZI, Misabel de Abreu Machado. Direito tributário, direito penal e tipo. São Paulo: Revista dos Tribunais, 1988

DOTTI, René Ariel. Curso de direito penal. Parte geral. Rio de Janeiro: Forense, 2002.

FARIA COSTA, José de. Relações entre a parte geral e a parte especial do Código Penal. Boletim da Faculdade de Direito da Universidade de

Coimbra, v.LXXI, p.118-144, Coimbra, 1995.

FERRAJOLI, Luigi. Derecho y razón. Teoría del garantismo penal. Madrid: Trotta, 1995.

FERREIRA, Manoel Cavaleiro de. Lições de direito penal - parte geral. 4.ed. Lisboa: Verbo, 1992

FEUERBACH, Anselm Von. Tratado de derecho penal. Buenos Aires Hamurabi, 1989.

FIGUEIREDO DIAS, Jorge de. Questões fundamentais de direito pena revisitadas. São Paulo: Revista dos Tribunais, 1999.

FONTÁN BALESTRA, Carlos. Tratado de derecho penal. 2.ed. Buenos Aires: Abelendo-Perrot, 1990.

FRAGOSO, Heleno Cláudio. Lições de direito penal. A nova parte geral. 11.ed., Rio de Janeiro: Forense, 1985.

Lições de direito penal. Parte especial. 6.ed. Rio de Janeiro: Ed Forense, 1981

GARCIA, Basileu. Instituições de direito penal. 5.ed. São Paulo: Max Limonad, 1980.

GRISPIGNI, Filippo. Diritto penale italiano. Milano: Giuffrè, 1950.

HUNGRIA, Nélson. Comentários ao código penal. 5.ed. Rio de Janeiro: Forense, 1982

JAKOBS, Günther. A imputação objetiva no direito penal. São Paulo: Revista dos Tribunais, 2000
JESUS, Damásio Evangelista de. Direito penal - parte geral. 25.ed revista e atualizada, São Paulo: Saraiva, 2002

JIMÉNEZ DE ASÚA, Luis. Tratado de derecho penal. Buenos Aires: Losada, 1950.

La ley y el delito. Caracas: Andrés Bello, 1945.

LISZT, Franz von. Tratado de derecho penal. 3.ed. Madrid: Réus, 1950

LYRA, Roberto. Direito penal normativo. 2.ed. Rio de Janeiro: José Konfino, 1977.

LOPES, Jair Leonardo. Curso de direito penal. 3.ed. São Paulo: Revista dos Tribunais, 1999

LUISI, Luiz. Os princípios constitucionais penais. Porto Alegre: Sérgio Fabris, 1991.

.O tipo penal, a teoria finalista e a nova legislação penal. Porto Alegre: Fabris, 1987

LUNA, Everardo da Cunha. Estrutura jurídica do crime. 4.ed. São Paulo: Saraiva, 1993.

MANZINI, Vincenzo. Trattato di diritto penale italiano. 2.ed. Torino Torinese, 1926

MARQUES, José Frederico. Curso de direito penal. São Paulo: Saraiva, 1954

Tratado de direito penal. São Paulo: Saraiva, 1961.

MÉDICI, Sérgio de Oliveira. Teoria dos tipos penais. São Paulo: Revista dos Tribunais, 2004

MEZGER, Edmund. Derecho penal. Parte especial. 4.ed. Córdoba: s/ed., 1954

MIRABETE, Júlio Fabbrini. Manual de direito penal. Parte geral. 17.ed. São Paulo: Atlas, 2001 
MIR PUIG, Santiago. Introducción a las bases del derecho penal. Barcelona: Ed. Bosch, 1982.

Derecho penal, parte general, Barcelona: PPU, 1985.

MUÑOZ CONDE, Francisco. Teoria geral do delito. Porto Alegre: Sérgio Antonio Fabris Ed, 1988.

Introduccion al derecho penal. Barcelona: Bosch, 1975

NAVARRETE, M. Polaino. El bien jurídico em el derecho penal.

Sevilha: Ed. de la Universidad, 1974.

NORONHA, Edgard Magalhães. Direito penal. 4.ed. São Paulo: Saraiva, 1965 .

NUVOLONE, Pietro. O sistema do direito penal. São Paulo: Revista dos Tribunais, 1981

PIERANGELLI, José Henrique. Códigos penais do Brasil - evolução histórica. Bauru: Jalovi, 1980.

PIERANGELLI, José Henrique; ZAFFARONI, Eugenio Raúl. Manual de direito penal brasileiro - parte geral. 3.ed. São Paulo: Revista dos

Tribunais, 2001

PRADO, Luiz Regis. Curso de direito penal brasileiro - parte geral. São Paulo: Revista dos Tribunais, 1999.

Bem jurídico-penal e constituição. São Paulo: Revista dos Tribunais, 1996

Teoria da imputação objetiva do resultado: uma abordagem crítica. Revista dos Tribunais, São Paulo, v. 798 (p. 445-460), abril de 2002.

PUIG PEÑA, Federico. Derecho Penal - parte especial, 6.ed. Madrid: Ed. Revista de Derecho Privado, 1969

REALE JÚNIOR, Miguel. Parte geral do Código Penal (nova interpretação). São Paulo: Revista dos Tribunais, 1988.
Teoria do delito. São Paulo: Revista dos Tribunais, 1998

RODRIGUES, Marta Felino. A teoria penal da omissão e a revisão crítica de Jakobs. Lisboa: Liv. Almedina, 2000.

RODRIGUEZ DEVESA, José Maria. Derecho penal español - parte especial. 6.ed. Madrid, 1975

ROXIN, Claus. Problemas fundamentais do direito penal. 2.ed. Lisboa: Ed. Veja, 1993

Funcionalismo e imputação objetiva no direito penal. Rio de Janeiro: Renovar, 2002

La parte general del derecho penal sustantivo, em Introducción al derecho penal y al derecho penal procesal. Sevilla: Ed. Univ. de Sevilla, 1988

1972

Política criminal y sistema del derecho penal. Barcelona: Bosch, 1982

Política criminal reforma del derecho penal. Bogotá: Ed. Temis,

Dogmática penal y política criminal. Lima: Idemsa, 1992.

TAVARES, Juarez. Teorias do delito. São Paulo: Revista dos Tribunais, 1980

TOLEDO, Francisco de Assis. Princípios básicos de direito penal. 4.ed. São Paulo: Saraiva, 1991

WELZEL, Hans. Derecho penal aleman. Parte general. 11.ed. Santiago: Ed. Jurídica de Chile. 1970

El nuevo sistema del derecho penal. Buenos Aires: Julio César Faira Ed., 2001.

WESSELS, Johannes. Direito penal. Porto Alegre: Sérgio A. Fabris Ed., 1976. 
ZAFFARONI, Eugenio Raúl. Manual de derecho penal - parte general.

2.ed. Buenos Aires: Ediar, 1979.

\section{Resumo:}

O trabalho se propõe a uma exposição didática das principais teorias relativas ao conceito genérico de crime, com vistas à plena compreensão do tema que estruturou cientificamente o Direito Penal. Trata-se de questão da maior relevância doutrinária, por propiciar a indicação das características comuns a todos os delitos em espécie e, conseqüentemente, a mais justa aplicação do Direito Criminal em qualquer país civilizado do mundo.

\section{Palavras-chave:}

Direito Penal, Crime, Fato Típico, Ação e Omissão, Teorias: Causalista, Finalista, Social e da Imputação Objetiva. 